\title{
Note from the Editor
}

\author{
Alan P. Dobson ${ }^{1}$
}

(๑) The Editor of the Journal 2019

I am delighted to welcome readers to the first issue of the JTS produced by our new publishers Palgrave Macmillan and also to introduce them to the largely refreshed editorial board. New opportunities and challenges are opening up, and the editorial team are ready to engage with them enthusiastically. I am delighted and excited by the composition of the new board and the promise it holds out for the future.

The line-up of issues for the coming year is really quite special, not least the current one on Kissinger with its international line-up of leading and rapidly rising scholars. This will be a hard act to follow, but both the standard issue and two other themed issues (on NATO and China) that are under preparation will not disappoint.

An important innovation with our new publisher is an annual $£ 2000$ research award jointly funded by Palgrave Macmillan and our sister organisation the Transatlantic Studies Association. The details for that award are included in this issue.

Finally, I would like to thank Nick Philipson for his help and engaging enthusiasm in transferring from Taylor and Francis. It was never going to be easy, but thanks to Nick and Jessica Banning, it has certainly not been hard. I and the new editorial board look forward to many years of fruitful collaboration with Palgrave Macmillan in disseminating scholarship on all aspects of the transatlantic region.

Professor Alan P. Dobson

Editor

Publisher's Note Springer Nature remains neutral with regard to jurisdictional claims in published maps and institutional affiliations.

Alan P. Dobson

a.p.dobson@swansea.ac.uk

1 Swansea University, Swansea, UK 